\title{
In patients with neovascular age-related macular degeneration, physical activity may influence $\mathrm{C}$-reactive protein levels
}

This article was published in the following Dove Press journal:

Clinical Ophthalmology

6 December 2013

Number of times this article has been viewed

Yousif Subhi

Amardeep Singh

Mads Krüger Falk

Torben Lykke Sørensen

Department of Ophthalmology, Clinical Eye Research Unit, Copenhagen University Hospital Roskilde and the University of Copenhagen, Copenhagen, Denmark
Correspondence: Torben Lykke Sørensen

Clinical Eye Research Unit, Department of Ophthalmology, Copenhagen University Hospital Roskilde,

7-I 3 Køgevej, Roskilde 4000, Denmark

$\mathrm{Tel}+4547323900$

$\mathrm{Fax}+4546362645$

Email torbenls@dadlnet.dk
Purpose: Association of neovascular age-related macular degeneration (AMD) with C-reactive protein (CRP) was previously reported, indicating a relation to systemic low-grade inflammation. However, visual impairment limits physical activity, and physical activity modulates CRP levels. Here, we investigated the impact of physical activity on CRP levels in patients with neovascular AMD and control individuals.

Subjects and methods: We recruited participants from our outpatient AMD program, and control individuals from non-AMD patients, visitors, and department staff. After initial screening of 191 individuals, we included 98 patients with neovascular AMD and 77 controls. All were screened using digital fundus photography and optical coherence tomography, and interviewed about medical history and physical activity. Venous blood samples were obtained for high-sensitivity CRP.

Results: Physically active individuals had lower CRP than physically inactive individuals $(P=0.003)$, and physical activity was associated with lower CRP in patients $(P=0.038)$ and controls $(P=0.031)$. Patients and controls did not differ in percentage physically active $(P=0.807)$ or in overall CRP levels $(P=0.394)$. The independent contribution of physical activity on CRP was confirmed in a multiple regression analysis $(P=0.009)$, in which the presence of neovascular AMD did not contribute significantly $(P=0.913)$.

Conclusion: Our findings suggest that elevated CRP levels in patients with neovascular AMD are at least partly explained by physical inactivity. Future studies of systemic inflammation among the visually impaired should include disease-related implications, such as the impact of physical activity.

Keywords: age-related macular degeneration, physical activity, C-reactive protein

\section{Introduction}

Age-related macular degeneration (AMD) is a major cause of visual impairment and blindness in the elderly worldwide. ${ }^{1}$ Profound vision loss is most distinct in neovascular AMD, which is a late stage of the disease. ${ }^{1}$ Neovascular AMD is characterized by the growth of newly formed choroidal neovascularizations, which protrude through Bruch's membrane, typically under the fovea, causing a decrease in vision due to leakage of fluid and hemorrhaging. ${ }^{2}$ Intravitreal injections of drugs are capable of halting the neovascularization through a blockade of vascular endothelial growth factor (VEGF); however, this current treatment regime does not provide a cure, but in most cases a stabilization of vision at a low level. ${ }^{3}$

AMD pathogenesis remains incompletely understood, but increasing evidence indicates a crucial role for inflammatory processes. ${ }^{2}$ One common marker of systemic 
inflammation is the hepatic secreted acute-phase reactant C-reactive protein (CRP), which also has been implicated in AMD $;{ }^{2}$ however, clinical studies seem inconsistent. ${ }^{4}$ Previous studies found associations between CRP elevation and such diseases as depression, ${ }^{5}$ type 2 diabetes, ${ }^{6}$ and cardiovascular diseases. ${ }^{7}$ Although inflammatory processes constitute a part of the pathogenesis in many diseases, a growing amount of evidence suggests that interpretation of CRP elevations should consider the impact of inflammatory comorbidities, such as aging, weight gain, or physical inactivity. $5,6,8$

Physical inactivity increases baseline CRP by decreased muscle-secreted hormones and cytokines. ${ }^{9,10}$ Muscular tissue constitutes around $40 \%$ of body weight, and is the largest endocrine organ in humans, thus its ability to modulate inflammatory activity is considerable, ${ }^{11}$ and one particular interesting aspect is that regular physical activity induces anti-inflammatory changes in blood, including a lower baseline CRP. ${ }^{12}$

Visually impaired patients with AMD are less physically active than individuals with normal visual capabilities. ${ }^{13,14}$ In this study, we evaluated whether the elevated CRP observed in patients with AMD is associated with the more sedentary lifestyle of visually impaired patients.

\section{Subjects and methods Study participants}

We included consecutive participants from our outpatient AMD program, and control individuals from non-AMD patients, visitors, and department staff. We aimed at agematching our control group by including only individuals of 60 years or older.

This study was approved by the Regional Committee of Ethics in Research of the Region of Zealand (SJ-142) and followed the tenets of the Declaration of Helsinki. Informed written and oral consent was obtained from all participants after explanation of the nature and possible consequences of the study.

\section{Inclusion and exclusion}

We photographed the macular area of all participants using Visucam NM/FA digital fundus photography (Carl Zeiss, Jena, Germany), optical coherence tomography scanning and fundus autofluorescence imaging using Spectralis HRA-OCT, SLO (Heidelberg Engineering, Heidelberg, Germany). Participants suspected of having neovascular AMD had fluorescein angiography and indocyanine green angiography to confirm diagnosis and to exclude other causes of maculopathy. Fluorescein angiography was done after venous blood sampling to avoid any potential interference.

We grouped participants as proposed in the Clinical AgeRelated Maculopathy Grading System (CARMS) and by two independent investigators. ${ }^{15}$ Our study only included control participants as CARMS grade 1 (0-9 small drusen present in the retina without pigment abnormalities), and cases as CARMS grade 5 (neovascular AMD, including nondrusenoid pigment epithelial detachments, serous retinal detachments, choroidal neovascular membrane with subretinal or subretinal pigment epithelium hemorrhages, or fibrosis).

We collected information about medical history and current medication use by a combination of interviews and electronic patient records. If participants or we were unsure of weight and height, these were measured. We categorized smoking habits into current smokers, former smokers (having previously consumed $>100$ cigarettes), or never smokers. ${ }^{16}$ Participants having quit smoking within the last year were categorized as current smokers. ${ }^{16}$ Alcohol consumption was reported as units (equivalent to $12 \mathrm{~g}$ ethanol) per week. We measured best-corrected visual acuity (BCVA) in both eyes using the Early Treatment Diabetic Retinopathy Study (ETDRS) chart. ${ }^{17}$

We included only participants without any known immunologic disease or cancer. We did not include participants if they were receiving immunomodulating therapy for any reason, or had received intravitreal anti-VEGF therapy for any reason within the last 30 days, or had been feeling unwell within the last 5 days. To avoid interference with other acutephase responses due to infections, or to avoid interference with potentially undiagnosed cancer, we excluded post hoc any participant with a CRP above $15 \mathrm{mg} \cdot \mathrm{L}^{-1} \cdot{ }^{18}$

\section{Physical activity}

We assessed physical activity by a single question, which has been validated in a previous study ${ }^{19}$ : "Do you currently participate in any regular activity or program (either on your own or in a formal class) designed to improve or maintain your physical fitness?" Outcome was patient reported as yes or no. Translation to Danish was performed by forward and backward translation. ${ }^{20}$

\section{CRP analysis}

We collected venous blood in $3.5 \mathrm{~mL}$ evacuated gel tubes containing lithium heparin. Plasma high-sensitivity CRP was measured with latex immunoassay using Architect CI8200 (Abbott Laboratories, Abbott Park, IL, USA) with a detection limit of $0.2 \mathrm{mg} \cdot \mathrm{L}^{-1}$. We took all samples between $8 \mathrm{am}$ 
and 10 am, and all measurements were done within 2 hours of phlebotomy.

\section{Statistical analysis}

Results are presented in median and interquartile range (IQR), since they were not normally distributed. We analyzed data using SPSS 20 (IBM Corp., Armonk, NY, USA). Continuous variables were compared using the MannWhitney $U$ test, and categorical variables were compared using the $\chi^{2}$ test. The relationship between CRP and various potentially influencing covariates (age, sex, physical activity, body mass index, alcohol consumption, smoking [current and former], and medical history [cardiovascular disease, hypertension, type 2 diabetes, and hypercholesterolemia]) were investigated in a multiple regression analysis using a stepwise forward approach. Due to the skewed distribution of CRP, we logarithmically transformed CRP into normal distribution to be used as the dependent outcome in the multiple regression analysis. We considered a $P$-value below 0.05 as significant.

\section{Results}

We screened 191 individuals, of whom 108 were patients and 83 were control individuals. We excluded post hoc eight patients and two controls as plasma CRP was above $15 \mathrm{mg} \cdot \mathrm{L}^{-1}$, one patient and four controls due to missing CRP data, and one patient due to missing data on physical activity. Thus, our analyses include 175 individuals, of whom 98 were patients and 77 were controls.

Table 1 shows characteristics of the study population. Patients and controls were comparable in sex, physical activity, body mass index, alcohol consumption, and medical history in term of comorbidities. Patients were slightly older than controls (Mann-Whitney $U$ test, $P<0.001$ ), and more patients than controls were current smokers $\left(\chi^{2}\right.$ test, $P=0.045)$. BCVA in the best- and worst-seeing eye were lower among patients compared with the controls (MannWhitney $U$ test, $P=0.001$ and $P<0.001$, for best- and worstseeing eye, respectively).

We found a trend similar to previous studies with fewer patients being physically active when the BCVA in the bestseeing eye was affected: we found 38 of 66 (58\%) patients with BCVA above 70 ETDRS letters to be physically active, while 16 of $30(53 \%)$ patients with moderately affected BCVA (between 35 and 70 ETDRS letters) in the best-seeing eye were physically active, and 0 of two $(0 \%)$ patients with severely affected BCVA (below 35 ETDRS letters) in the best-seeing eye were physically active.
Table I Characteristics of study population $(n=175)$

\begin{tabular}{|c|c|c|c|}
\hline & $\begin{array}{l}\text { Patients with } \\
\text { neovascular } \\
\text { AMD }(n=98)\end{array}$ & $\begin{array}{l}\text { Controls } \\
(n=77)\end{array}$ & $P$-value \\
\hline Age, years (range) & $76(70-82)$ & $69(65-76)$ & $<0.00 I^{\mathrm{a}}$ \\
\hline Female, $n(\%)$ & $59(60 \%)$ & $43(56 \%)$ & $0.56 \mathrm{I}^{\mathrm{b}}$ \\
\hline \multicolumn{4}{|c|}{ Best-corrected visual acuity } \\
\hline $\begin{array}{l}\text { Best-seeing eye, } \\
\text { ETDRS letters (range) }\end{array}$ & $76(65-83)$ & $83(76-85)^{d}$ & $<0.00 I^{\mathrm{a}}$ \\
\hline $\begin{array}{l}\text { Worst-seeing eye, } \\
\text { ETDRS letters (range) }\end{array}$ & $51(22-70)$ & $76(63-83)^{d}$ & $<0.00 I^{a}$ \\
\hline Physically active, n (\%) & $54(55 \%)$ & $4 \mathrm{I}(53 \%)$ & $0.807^{b}$ \\
\hline $\begin{array}{l}\text { Body mass index, } \\
\mathrm{kg} \cdot \mathrm{m}^{-2} \text { (range) }\end{array}$ & $25(23-28)^{c}$ & $26(24-30)^{d}$ & $0.055^{\mathrm{a}}$ \\
\hline $\begin{array}{l}\text { Alcohol consumption, } \\
\text { units/week (range) }\end{array}$ & $4(0-7)$ & $4(1-10)$ & $0.322^{\mathrm{a}}$ \\
\hline \multicolumn{4}{|l|}{ Smoking, n (\%) } \\
\hline Current smoker & $23(23 \%)$ & $9(12 \%)$ & $0.045^{b}$ \\
\hline Former smoker & $39(40 \%)$ & $35(46 \%)$ & $0.452^{b}$ \\
\hline \multicolumn{4}{|l|}{ Medical history, n (\%) } \\
\hline Cardiovascular disease & $38(39 \%)$ & $22(29 \%)$ & $0.158^{b}$ \\
\hline Hypertension & $63(64 \%)$ & $42(55 \%)$ & $0.192^{b}$ \\
\hline Type 2 diabetes & $10(10 \%)$ & $15(19 \%)$ & $0.082^{b}$ \\
\hline Hypercholesterolemia & $27(28 \%)$ & $17(22 \%)$ & $0.413^{b}$ \\
\hline
\end{tabular}

Notes: a Mann-Whitney $U$ test; ${ }^{b} \chi^{2}$ test; ${ }^{c}$ missing data for four patients; ${ }^{d}$ missing data for one control.

Abbreviations: AMD, age-related macular degeneration; ETDRS, Early Treatment Diabetic Retinopathy Study.

In general, CRP was lower in physically active participants (1.6 $\mathrm{mg} \cdot \mathrm{L}^{-1}$, IQR $0.7-3.1 \mathrm{mg} \cdot \mathrm{L}^{-1}$ ) compared with physically inactive participants $\left(2.1 \mathrm{mg} \cdot \mathrm{L}^{-1}, \mathrm{IQR} 1.3-4.8 \mathrm{mg} \cdot \mathrm{L}^{-1}\right)$ (Mann-Whitney $U$ test, $P=0.003$ ) (Figure 1 ). Physically active patients had lower CRP $\left(1.7 \mathrm{mg} \cdot \mathrm{L}^{-1}\right.$, IQR $\left.0.7-3.3 \mathrm{mg} \cdot \mathrm{L}^{-1}\right)$ than the physically inactive patients $\left(2.1 \mathrm{mg} \cdot \mathrm{L}^{-1}\right.$, IQR $\left.1.4-4.5 \mathrm{mg} \cdot \mathrm{L}^{-1}\right)$ (Mann-Whitney $U$ test, $\left.P=0.038\right)$. Similarly, physically active controls had lower CRP $\left(1.4 \mathrm{mg} \cdot \mathrm{L}^{-1}\right.$, IQR $0.7-2.5 \mathrm{mg} \cdot \mathrm{L}^{-1}$ ) than the physically inactive controls $\left(2.1 \mathrm{mg} \cdot \mathrm{L}^{-1}\right.$, IQR $\left.1.2-4.9 \mathrm{mg} \cdot \mathrm{L}^{-1}\right)$ (Mann-Whitney $U$ test, $P=0.031)$ (Figure 1). Physically active patients $\left(1.7 \mathrm{mg} \cdot \mathrm{L}^{-1}\right.$, IQR $0.7-3.3 \mathrm{mg} \cdot \mathrm{L}^{-1}$ ) and physically active controls (1.4 mg $\cdot \mathrm{L}^{-1}$, IQR $0.7-2.5 \mathrm{mg} \cdot \mathrm{L}^{-1}$ ) did not differ significantly (Mann-Whitney $U$ test, $P=0.443$ ). Similarly, physically inactive patients $\left(2.1 \mathrm{mg} \cdot \mathrm{L}^{-1}, \mathrm{IQR} 1.4-4.5 \mathrm{mg} \cdot \mathrm{L}^{-1}\right)$ and physically inactive controls $\left(2.1 \mathrm{mg} \cdot \mathrm{L}^{-1}, \mathrm{IQR} 1.2-4.9 \mathrm{mg} \cdot \mathrm{L}^{-1}\right)$ did not differ significantly (Mann-Whitney $U$ test, $P=0.625$ ) (Figure 1). We found no significant difference in CRP between all patients $\left(1.9 \mathrm{mg} \cdot \mathrm{L}^{-1}\right.$, IQR $\left.1.1-3.7 \mathrm{mg} \cdot \mathrm{L}^{-1}\right)$ and all controls $\left(1.7 \mathrm{mg} \cdot \mathrm{L}^{-1}\right.$, IQR $\left.1.0-3.4 \mathrm{mg} \cdot \mathrm{L}^{-1}\right)(\mathrm{Mann}-$ Whitney $U$ test, $P=0.394$ ) (Figure 1).

We used a multiple regression analysis to adjust for potential confounding factors on CRP. CRP values were logarithmically transformed into normal distribution 
A

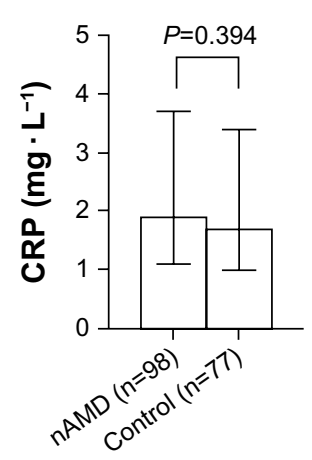

C
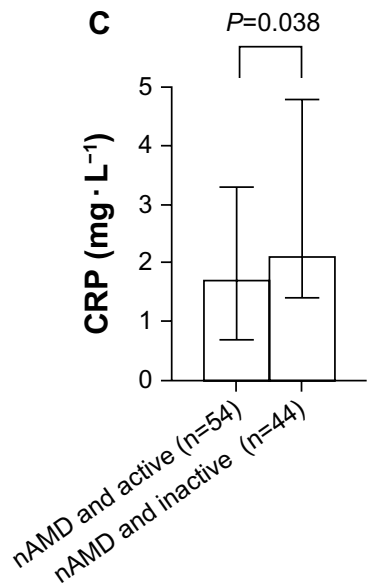

E
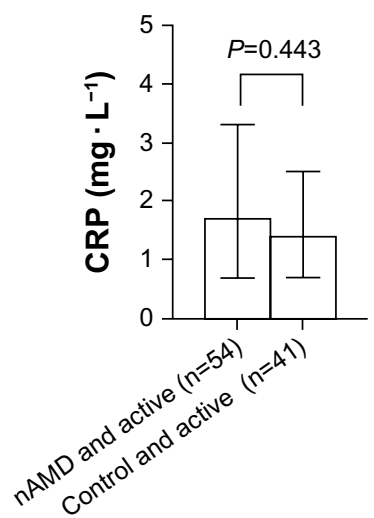

B $\quad P=0.003$

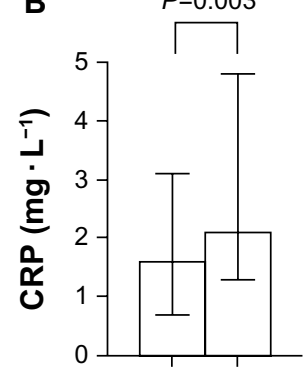

(2) 800

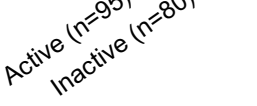

D $\quad P=0.031$
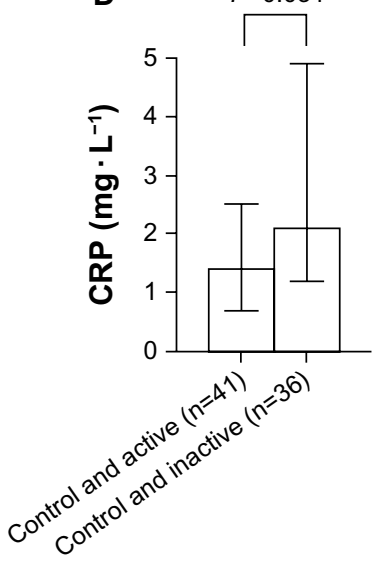

$\mathbf{F}$
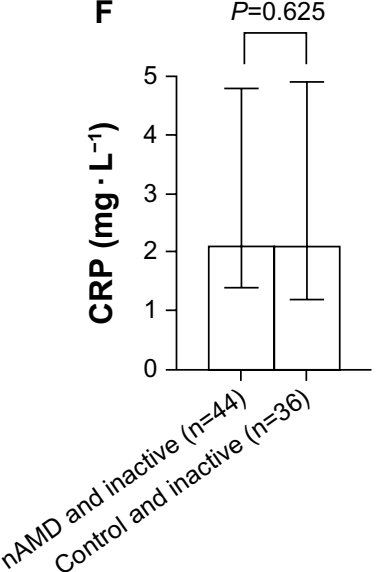

Figure I (A-F) Comparison of C-reactive protein (CRP) levels between patients with neovascular age-related macular degeneration (nAMD) and control individuals, and between physically active and physically inactive individuals. Bars represent median values and whiskerlimits represent interquartile range. $P$-values are based on the Mann-Whitney $U$ test. CRP did not differ between patients with nAMD and control individuals (A), CRP was significantly lower among the physically active when compared with the physically inactive (B), and this pattern was also found within the group of patients with nAMD (C), and control individuals (D), Physically active patients with nAMD and controls did not differ in CRP (E), and physically inactive patients and controls did not differ in CRP (F).

(Kolmogorov-Smirnov Test, $P=0.877$ ), and were included in the multiple regression analysis as the dependent outcome. Five cases were excluded due to missing data (missing data on body mass index for four patients and one control). We found CRP to be independently influenced by physical activity
( $P=0.009)$, body mass index $(P<0.001)$, being a current smoker $(P<0.001)$ or former smoker $(P<0.001)$, and having a history of hypertension $(P=0.001)$ or hypercholesterolemia ( $P=0.017$ ) (adjusted $R^{2}=0.260$ ). Our model did not include other covariates in the analysis, as they did not contribute significantly. Adding the presence of neovascular AMD into the analysis as a covariate did not improve the model, as the analysis did not include the covariate due to nonsignificant contribution $(P=0.913)$ to the model.

\section{Discussion}

We found physical activity to influence CRP levels in patients with neovascular AMD. We did not find elevated CRP levels in patients with neovascular AMD. This suggests that CRP levels in neovascular AMD may reflect lifestyle, rather than being disease-specific.

Physical activity and body mass index are two well-studied lifestyle factors, which modulate baseline CRP levels. Regular physical activity has anti-inflammatory effects mediated by muscle-secreted cytokines. ${ }^{11}$ An acute bout of exercise temporarily increases interleukin (IL)-6 manyfold, ${ }^{11}$ which then inhibits tumor necrosis factor (TNF)- $\alpha$ production. ${ }^{21}$ Exercising regularly leads to sustained lower baseline levels of TNF- $\alpha .{ }^{22,23}$ Exercise-induced IL-6 peaks increase muscular and adipose fatty acid oxidation, which lead to a decrease in adipose tissue mass. ${ }^{24,25}$ The decrease in adipose tissue mass is also partly explained by the energy expenditure from being physically active and by the energy spent on maintenance of the muscle mass. ${ }^{26} \mathrm{As}$ adipose tissue is a major contributor to baseline IL- $6,{ }^{27}$ less adipose tissue leads to less total adipose IL- $6 .{ }^{28}$ In conclusion, regular physical activity lowers baseline levels of IL- 6 and TNF- $\alpha$, and as the secretion of CRP is primarily dependent on IL- 6 and TNF- $\alpha,{ }^{29}$ regular physical activity leads to lower CRP levels. ${ }^{12}$ Conversely, physical inactivity and sedentary lifestyle are associated with elevated CRP. ${ }^{30} \mathrm{In}$ our study, we found physically active individuals to have lower $\mathrm{CRP}$, and physically inactive individuals to have higher CRP (a $0.5 \mathrm{mg} \cdot \mathrm{L}^{-1}$ difference in medians in our study sample).

Patients with neovascular AMD are more likely to have mobility limitations and to be physically inactive due to visual impairment. ${ }^{13,14}$ One study demonstrated this by using accelerometers to measure physical activity among the visually impaired, and found that visual impairment leads to a lower number of steps taken per day and less time spent on moderate or vigorous physical activity, and that this relationship is particularly distinct when patients have moderate or severe visual impairment in their better eye. ${ }^{14}$ Interestingly, we also found a small difference in physical activity between patients with unilateral visual impairment 
and patients with moderate visual impairment in their better eye, while no patients with severe visual impairment were physically active. One should note, however, that we only had a few cases in the latter group, which may explain why our patient and control groups did not differ significantly in the overall prevalence of physical activity. The difference in physical activity between patients with unilateral visual impairment and patients with moderate visual impairment being small (58\% and 53\%, respectively) may explain why we did not find a significant difference in CRP between these groups (data not shown).

Several cofactors were associated with higher CRP in our study (history of hypertension or hyperlipidemia, current or former smoking habits, and high body mass index), which are in agreement with findings in previous studies of CRP in patients with AMD. ${ }^{4}$ In addition, we also found physical activity to be associated with lower CRP in patients with AMD. A case-control study of patients with late AMD and control individuals found AMD to be associated with high CRP levels (>6.5-117.0 $\mathrm{mg} \cdot \mathrm{L}^{-1}$ ) (odds ratio 1.65 [1.07-2.55]). ${ }^{31}$ Two studies linked an association between AMD and CRP to a higher prevalence of cardiovascular disease among patients with AMD. ${ }^{32,33} \mathrm{CRP}$ levels of $1-3 \mathrm{mg} \cdot \mathrm{L}^{-1}$ and $>3 \mathrm{mg} \cdot \mathrm{L}^{-1}$ are considered moderate risk and high risk, respectively, for development of future cardiovascular diseases. ${ }^{34}$ In our study, physically inactive patients with neovascular AMD had a median CRP of $2.1 \mathrm{mg} \cdot \mathrm{L}^{-1}$, which suggests that more than half of our physically inactive patients were at moderateto-high risk of developing future cardiovascular diseases. It is therefore not unlikely that an association between neovascular AMD, CRP, and cardiovascular diseases is at least partly mediated by physical inactivity. Future studies may investigate this potential relationship.

The importance of lifestyle factors on CRP is also reflected by differences in previous studies, which may play a role in the inconsistent conclusions on whether or not elevated CRP is associated with AMD. For example, adjustment of influencing factors, such as diseases and lifestyle factors that influence CRP levels, differs among the previous studies. ${ }^{4} \mathrm{~A}$ number of other issues may play a role in CRP levels: severity of AMD in the study population (conclusions from some previous studies are based on patients with AMD before the introduction of anti-VEGF treatment, and the patients may thus have been more visually impaired and physically inactive), differences in the prevalence of comorbidities in the study population that affect physical activity, or differences in cultural or environmental factors (for example, cycling is common among the elderly in Denmark, but this may not be the case in other countries). Therefore, using a study sample with a low prevalence of bilaterally visually impaired and physically inactive individuals, we may not find that patients have elevated CRP compared with controls. Other study populations may find elevated CRP in patients using a study sample with a higher prevalence of bilaterally visually impaired and physically inactive individuals. Future studies should consider the impact of AMD-associated lifestyle when investigating associations with CRP. The impact of physical activity was more attenuated in the AMD group compared to the control group; however, this difference should be interpreted with caution, as this study was not designed to show an interventional effect of physical activity on baseline CRP levels, since this would require an interventional longitudinal study. A possible explanation of this observed difference could be a potential difference in physical activity intensity between the two groups.

Our study has several strengths. We had a comprehensive retinal imaging protocol for disease grading. Potential participants feeling unwell were not included, and we excluded cases with CRP above $15 \mathrm{mg} \cdot \mathrm{L}^{-1}$ to avoid interference with an acute-phase response from infections. ${ }^{18}$ We included consecutively to minimize any selection bias. Information about disease and medication use is patient-based, and there is a potential possibility of patients not giving all information, and we addressed this bias by checking electronic patient records for relevant information. However, this approach does not adjust for undiagnosed conditions, which may influence the measured CRP levels. Without using accelerometers, the validity of physical activity questionnaires to determine the extent and characteristics of physical activity is very low. ${ }^{35}$ Although accelerometers may be more valid in general, when used on the elderly, only studies with small samples and multiple (two biaxial) accelerometers have been able to yield very accurate results. ${ }^{36} \mathrm{We}$ used a validated single question for physical activity assessment, ${ }^{19}$ and this approach is valid and preferred for screening purposes of general physical activity level, ${ }^{37}$ but does not provide an in-depth picture of physical activity characteristics. Our cases and controls were different with regard to age and current smoking, which potentially may overshadow an actual difference between controls and patients with AMD. We did not find age to be associated with CRP levels, but current smoking was associated with a higher CRP. Rerunning the analysis without including the current smokers gave us similar results (data not shown) and did not change our conclusions.

\section{Conclusion}

We show that in patients with neovascular AMD, physical activity may influence CRP levels. Our findings suggest that an association between CRP and neovascular AMD should 
be interpreted with caution, as physical inactivity may interfere. We encourage future studies to consider the impact of visual impairment on confounding lifestyle factors, such as physical activity, when investigating levels of low-grade inflammation in the visually impaired. In this way, we may obtain a clearer picture of the pathogenesis and possible targets for treatment.

\section{Acknowledgment}

This study was supported by the Lundbeck Foundation.

\section{Disclosure}

The authors report no conflicts of interest in this work.

\section{References}

1. Lim LS, Mitchell P, Seddon JM, Holz FG, Wong TY. Age-related macular degeneration. Lancet. 2012;379(9827):1728-1738.

2. Ding X, Patel M, Chan C. Molecular pathology of age-related macular degeneration. Prog Retin Eye Res. 2009;28(1):1-18.

3. Krüger Falk M, Kemp H, Sørensen TL. Four year treatment results of neovascular age-related macular degeneration with ranibizumab and causes for discontinuation of treatment. Am J Ophthalmol. 2013;155(1):89-95. e3.

4. Hong T, Tan AG, Mitchell P, Wang JJ. A review and meta-analysis of the association between C-reactive protein and age-related macular degeneration. Surv Ophthalmol. 2011;56(3):184-194.

5. Howren MB, Lamkin DM, Suls J. Associations of depression with C-reactive protein, IL-1, and IL-6: a meta-analysis. Psychosom Med. 2009;71(2):171-186.

6. Lee CC, Adler AI, Sandhu MS, et al. Association of C-reactive protein with type 2 diabetes: prospective analysis and meta-analysis. Diabetologia. 2009;52(6):1040-1047.

7. Emerging Risk Factors Collaboration; Kaptoge S, Di Angelantonio E, et al. C-reactive protein concentration and risk of coronary heart disease, stroke, and mortality: an individual participant meta-analysis. Lancet. 2010;375(9709):132-140.

8. Singh T, Newman AB. Inflammatory markers in population studies of aging. Ageing Res Rev. 2011;10(3):319-329.

9. Esteghamati A, Morteza A, Khalilzadeh O, et al. Physical inactivity is correlated with levels of quantitative C-reactive protein in serum, independent of obesity: results of the national surveillance of risk factors of non-communicable diseases in Iran. J Health Popul Nutr. 2012;30(1):66-72.

10. Schaap LA, Pluijm SM, Deeg DJ, et al. Higher inflammatory marker levels in older persons: associations with 5-year change in muscle mass and muscle strength. J Gerontol A Biol Sci Med Sci. 2009;64(11): 1183-1189.

11. Pedersen BK, Febbraio MA. Muscles, exercise and obesity: skeletal muscle as a secretory organ. Nat Rev Endocrinol. 2012;8(8):457-465.

12. Kasapis C, Thompson PD. The effects of physical activity on serum C-reactive protein and inflammatory markers: a systematic review. J Am Coll Cardiol. 2005;45(10):1563-1569.

13. Popescu ML, Boisjoly H, Schmaltz H, et al. Age-related eye disease and mobility limitations in older adults. Invest Ophthalmol Vis Sci. 2011;52(10):7168-7174.

14. Willis JR, Jefferys JL, Vitale S, Ramulu PY. Visual impairment, uncorrected refractive error, and accelerometer-defined physical activity in the United States. Arch Ophthalmol. 2012;130(3):329-335.

15. Seddon JM, Sharma S, Adelman RA. Evaluation of the clinical age-related maculopathy staging system. Ophthalmology. 2006;113(2):260-266.
16. Freedman ND, Leitzmann MF, Hollenbeck AR, Schatzkin A, Abnet CC. Cigarette smoking and subsequent risk of lung cancer in men and women: analysis of a prospective cohort study. Lancet Oncol. 2008;9(7):649-656.

17. Kaiser PK. Prospective evaluation of visual acuity assessment: a comparison of snellen versus ETDRS charts in clinical practice (an AOS thesis). Trans Am Ophthalmol Soc. 2009;107:311-324.

18. Rifai N, Ridker PM. Proposed cardiovascular risk assessment algorithm using high-sensitivity $\mathrm{C}$-reactive protein and lipid screening. Clin Chem. 2001;47(1):28-30.

19. Schechtman KB, Barzilai B, Rost K, Fisher EB Jr. Measuring physical activity with a single question. Am J Public Health. 1991;81(6): 771-773.

20. Acquadro C, Jambon B, Ellis D, Marquis P. Language and translation issues. In: Spilker B, editor. Quality of Life and Pharmacoeconomics in Clinical Trials. Philadelphia: Lippincott-Raven; 1996:575-585.

21. Starkie R, Ostrowski SR, Jauffred S, Febbraio M, Pedersen BK. Exercise and IL-6 infusion inhibit endotoxin-induced TNF-alpha production in humans. FASEB J. 2003;17(8):884-886.

22. Lambert CP, Wright NR, Finck BN, Villareal DT. Exercise but not diet-induced weight loss decreases skeletal muscle inflammatory gene expression in frail obese elderly persons. J Appl Physiol. 2008;105(2): 473-478.

23. Pedersen BK, Bruunsgaard H. Possible beneficial role of exercise in modulating low-grade inflammation in the elderly. Scand J Med Sci Sports. 2003;13(1):56-62.

24. Bruce CR, Dyck DJ. Cytokine regulation of skeletal muscle fatty acid metabolism: effect of interleukin-6 and tumor necrosis factor-alpha. Am J Physiol Endocrinol Metab. 2004;287(4):E616-E621.

25. Petersen EW, Carey AL, Sacchetti M, et al. Acute IL-6 treatment increases fatty acid turnover in elderly humans in vivo and in tissue culture in vitro. Am J Physiol Endocrinol Metab. 2005;288(1):E155-E162.

26. Speakman JR, Selman C. Physical activity and resting metabolic rate. Proc Nutr Soc. 2003;62(3):621-634.

27. Mohamed-Ali V, Goodrick S, Rawesh A, et al. Subcutaneous adipose tissue releases interleukin-6, but not tumor necrosis factor-alpha, in vivo. J Clin Endocrinol Metab. 1997;82(12):4196-4200.

28. Vendrell J, Broch M, Vilarrasa N, et al. Resistin, adiponectin, ghrelin, leptin, and proinflammatory cytokines: relationships in obesity. Obes Res. 2004;12(6):962-971.

29. Gabay C, Kushner I. Acute-phase proteins and other systemic responses to inflammation. N Engl J Med. 1999;340(6):448-454.

30. Fischer CP, Berntsen A, Perstrup LB, Eskildsen P, Pedersen BK. Plasma levels of interleukin-6 and C-reactive protein are associated with physical inactivity independent of obesity. Scand J Med Sci Sports. 2007; 17(5):580-587.

31. Seddon JM, Gensler G, Milton RC, Klein ML, Rifai N. Association between $\mathrm{C}$-reactive protein and age-related macular degeneration. JAMA. 2004;291(6):704-710.

32. Dasch B, Fuhs A, Behrens T, et al. Inflammatory markers in age-related maculopathy: cross-sectional analysis from the Muenster Aging and Retina Study. Arch Ophthalmol. 2005;123(11):1501-1506.

33. Hogg RE, Woodside JV, Gilchrist SE, et al. Cardiovascular disease and hypertension are strong risk factors for choroidal neovascularization. Ophthalmology. 2008;115(6):1046-1052. e2.

34. Ridker PM. Clinical application of C-reactive protein for cardiovascular disease detection and prevention. Circulation. 2003;107(3): 363-369.

35. Helmerhorst HJ, Brage S, Warren J, Besson H, Ekelund U. A systematic review of reliability and objective criterion-related validity of physical activity questionnaires. Int J Behav Nutr Phys Act. 2012;9:103.

36. Cheung VH, Gray L, Karunanithi M. Review of accelerometry for determining daily activity among elderly patients. Arch Phys Med Rehabil. 2011;92(6):998-1014.

37. Milton K, Clemes S, Bull F. Can a single question provide an accurate measure of physical activity? Br J Sports Med. 2013;47(1):44-48. 


\section{Publish your work in this journal}

Clinical Ophthalmology is an international, peer-reviewed journal covering all subspecialties within ophthalmology. Key topics include: Optometry; Visual science; Pharmacology and drug therapy in eye diseases; Basic Sciences; Primary and Secondary eye care; Patien Safety and Quality of Care Improvements. This journal is indexed on Submit your manuscript here: http://www.dovepress.com/clinical-ophthalmology-journal

\section{Dovepress}

PubMed Central and CAS, and is the official journal of The Society of Clinical Ophthalmology (SCO). The manuscript management system is completely online and includes a very quick and fair peer-review system, which is all easy to use. Visit http://www.dovepress.com/ testimonials.php to read real quotes from published authors. 